\title{
Stevens-Johnson Syndrome (SJS) and Toxic Epidermal Necrolysis (TEN)
}

\author{
Immunologic Reactions
}

\section{Danielle Zimmerman and Nam Hoang Dang}

\section{Contents}

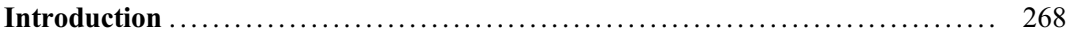

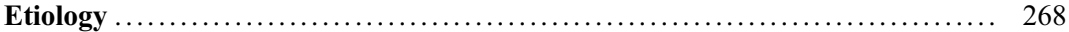

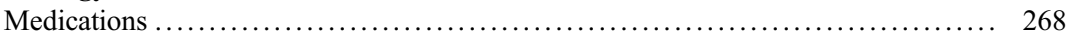

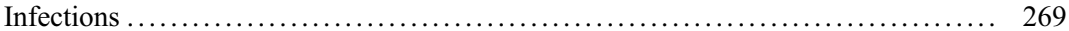

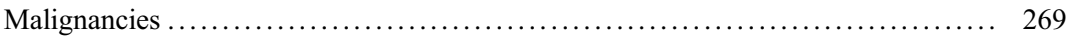

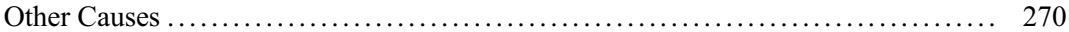

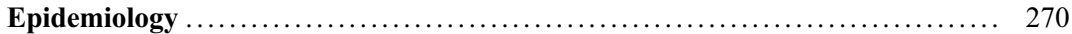

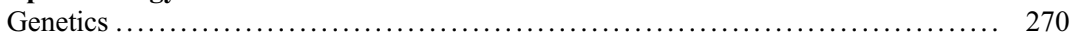

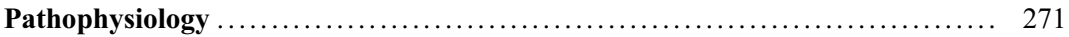

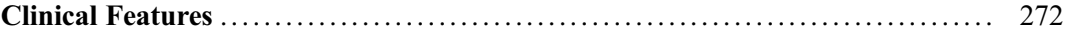

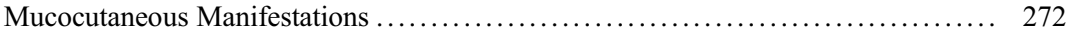

Ophthalmologic Manifestations ........................................ 273

Bronchial Manifestations ......................................... 273

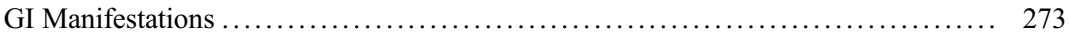

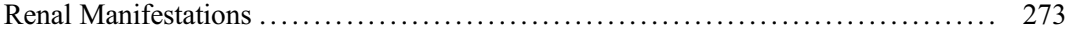

Hematologic Manifestations ........................................ 273

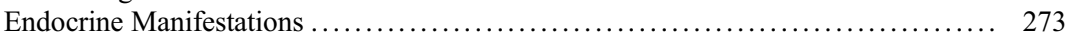

Other Manifestations and Laboratory Markers .......................... 273

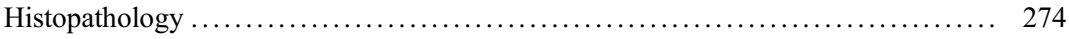

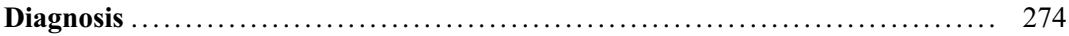

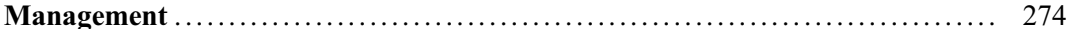

Nonpharmacologic Management/Supportive Care .......................... 274

Pharmacologic Management .............................................. 275

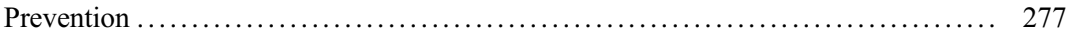

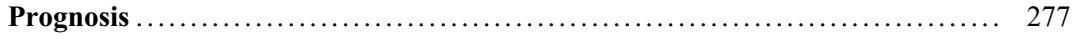

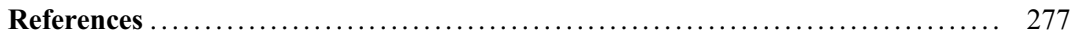

D. Zimmerman · N. H. Dang $(\bowtie)$

University of Florida Health Cancer Center,

Gainesville, FL, USA

e-mail: danielle.zimmerman@medicine.ufl.edu; nam.dang@medicine.ufl.edu 


\section{Abstract}

Stevens-Johnson syndrome (SJS) and toxic epidermal necrolysis (TEN) are immunologic reactions to several stimuli, mostly medications, which present as a spectrum of primarily widespread mucocutaneous lesions, but also with other organ involvement. Pathology is characterized by full thickness necrosis of the epithelial layer of the involved organ due to immune-mediated apoptosis of the resident keratinocytes. High suspicion for early detection and quick withdrawal of the culprit medication are the most important steps in stopping this reaction. Aggressive supportive care is often necessary as the patient recovers. Steroids, other immunosuppressants, and plasmapheresis have all been studied as treatments, but high-quality evidence supporting their contributions, either together or separately, in decreasing length of hospital stay or prolonging survival have not been consistently demonstrated. Further studies of the mechanism of action and novel treatment modalities are still needed to improve outcomes in patients with this rare but often fatal condition.

\section{Keywords}

Bullous lesion - Mucocutaneous involvement • Steroids $\cdot$ Stevens-Johnson syndrome $\cdot$ Toxic epidermal necrolysis

\section{Introduction}

Toxic epidermal necrolysis (TEN) and Stevens-Johnson syndrome (SJS) are potentially life-threatening type IVc immune reactions with inflammation mediated by cytotoxic $\mathrm{T}$ lymphocytes, that present with mucocutaneous blistering reactions with epidermal detachment and extensive necrosis [62].

The skin reaction is termed SJS when less than $10 \%$ of the body surface area (BSA) is involved. The intermediate form is classified as SJS/TEN and has $10-30 \%$ skin involvement. TEN describes the skin reaction when greater than $30 \%$ of the BSA is involved. Greater than $90 \%$ of patients with SJS have mucous membrane involvement, and nearly all patients will have mucous membrane involvement in TEN [54]. The overall range of disease will henceforth be referred to as SJS and TEN in this discussion. The whole spectrum of this disorder can involve other organs, which can complicate treatment and convalescence [69].

Epidermal cell necrosis is caused by aberrant immune activation by a variety of stimuli but mostly medications. Cytotoxic $\mathrm{T}$ lymphocytes are induced with CD4+ cells and innate immune cells to secrete granulysin and other cytokines that puncture the cell membrane and cause sufficient damage to induce widespread apoptosis in a rapid fashion [12].

\section{Etiology}

While approximately $5-20 \%$ of cases remain idiopathic [66], SJS and TEN are thought to be due to a combination of immune predisposition and exogenous stimuli such as medication [43] or infection that results in apoptosis of epithelial cells [59]. Medication exposure is associated with $50-95 \%$ of cases, depending on the population examined [55].

People with certain HLA serotypes, TCR subtypes, or differences in their ability to absorb, distribute to tissues, metabolize, or excrete medications have a higher likelihood of developing SJS and TEN [59].

\section{Medications}

There are 100-200 medications associated with the development of SJS and TEN. Though this group of medications includes many antibiotics and sulfa-containing compounds, there is no existing test to determine definitively if a given medication was responsible for causing the skin reaction [66]. However, there is an algorithm of drug causality for epidermal necrolysis (ALDEN) that was constructed to improve the individual assessment of medication causality in SJS and TEN [66]. 
A small selection of these medications causes about half of all cases of SJS and TEN oxicam NSAIDs; phenylbutzone; sulfonamides such as sulfamethoxazole, sulfadiazine, sulfapyridine, sulfadoxine, sulfasalazine; allopurinol; lamotrigine; nevirapine; phenytoin; and carbamazepine [62]. Acetaminophen has been identified as a possible cause in children but not in adults [59]. A review of severe skin reactions from 1950 to 2013 associated with antineoplastic agents revealed that the following medications have been strongly correlated with SJS and TEN: bendamustine, procarbazine, fludarabine, busulfan, chlorambucil, and lomustine [54]. Other drugs that can cause SJS and TEN include vancomycin, valproate, levofloxacin, etravirine, isotretinoin, quinolones, diclofenac, fluconazole, sitagliptin, oseltamivir, penicillins, barbiturates, sulfonamides, azithromycin, oxcarbazepine, zonisamide, modafinil, pyrimethamine, ethosuximide, bupropion, telaprevir, nystatin, cefixime, and trimethoprim [59].

Some medications that have been investigated but not found to have a strong link to development of SJS and TEN include aspirin, sulfonylureas, vitamins, thiazide diuretics, furosemide, aldactone, calcium channel blockers, beta blockers, hormones, angiotensin-converting enzyme inhibitors, angiotensin II receptor antagonists, and statins.

\section{Infections}

Mycoplasma pneumoniae is the most common bacterial infection associated with the development of SJS and TEN. Infection with this microorganism is noted to be the cause of SJS and TEN more often in children than in adults, and treatment of the infection has led to improvement of skin symptoms in some cases [31]. Less common bacterial agents implicated in its development include Yersinia, tuberculosis, syphilis, chlamydia, Streptococci, Salmonella, Enterobacter, and Pneumococcus [59].

Coccidiomycosis and histoplasmosis are the potential fungal causes of SJS and TEN [59]. Strongyloides infection was also associated with SJS and TEN in a case report [7].
The incidence of SJS and TEN in patients with HIV is about one thousand times higher than the incidence in patients without HIV [29]. This is likely due in part to the increased likelihood of HIV patients being exposed to potential culprit medications such as sulfonamides, but other cases are attributable to the HIV infection itself. Other viruses that may play a role in the pathogenesis of SJS and TEN include enterovirus, adenovirus, measles, mumps, CMV [29], herpes simplex, HHV-6, and influenza [59]. HHV has been recognized as a causative agent for SJS and TEN for several cases in children in particular. Some viral infections have been shown to increase expression of Fas ligand or sensitivity to Fas ligand-mediated apoptosis [29], but the importance of Fas ligand expression may have been overestimated, both overall and in virally induced cases of SJS and TEN. Speculation exists that changes to immune cell activity in keratinocytes induced by infection contributes to development of SJS and TEN in these cases.

\section{Malignancies}

Patients with hematologic malignancies, and to a lesser extent nonhematologic malignancies, have a higher risk of developing SJS and TEN. It is not known if the malignancies themselves, disrupted immune function, or exposure to a higher variety of pharmacologic agents is the key variable responsible in this patient cohort [41]. The magnitude of this risk has been estimated to be between two [18] and as much as sixty [70] times that of the patient without any malignancy, but this variance may depend on the patient population examined. Diagnoses of hepatocellular carcinoma and colorectal cancer (but not hematologic malignancy, lung cancer, or urothelial carcinoma), abnormal labs, and recent or current chemotherapy administration were associated with higher risks of death in a recent review of patients in the UK [68]. A study of patients in the USA found that SJS and TEN were most associated with multiple myeloma, leukemia, non-Hodgkin's lymphoma, and CNS malignancies [25]. An earlier review of patients at a 
Roman hospital indicated that CNS malignancy and NHL were the most common malignancies associated with SJS and TEN [23].

\section{Other Causes}

There are rare cases in which vaccinations have been thought to lead to SJS and TEN, including the smallpox vaccination, the diphtheriapertussis-tetanus (DPT) vaccination, Bacillus Calmette-Guérin (BCG) vaccination, and the measles-mumps-rubella (MMR) vaccination [55].

Cases of SJS and TEN have been reported after allogenic bone marrow transplantation; however, these cases have been difficult to distinguish from severe graft versus host disease due to similarity of skin appearance on exam and histology. Radiation therapy, inflammatory bowel disease, administration of IV contrast, and toxic chemical exposure have rarely been implicated in cases of SJS and TEN [62]. The cases of SJS and TEN associated with inflammatory bowel disease may have been associated with anti-TNF alpha therapy rather than the disease itself.

\section{Epidemiology}

The incidence of SJS and TEN is about one or two cases per one million people. TEN and SJS have been known to occur in patients of all ages, but the highest incidence is in adults greater than 40 years old [59]. Incidence is about equal in men and women [30]. Most cases tend to occur in winter or early spring, which could correlate with antibiotic prescriptions [18].

An observational study of patients with SJS and TEN in the UK indicated patients of African or Asian ancestry had twice the chance of developing SJS and TEN compared with white patients; however, the general applicability of the study is limited by the low sample size. Higher incidence in patients with epilepsy, gout, and autoimmune diseases was thought to be largely attributable to associated medications rather than to the diseases themselves. No association was found between SJS and TEN and tobacco use, alcohol use, or obesity [18].

\section{Genetics}

There appears to be a predilection for developing SJS and TEN in reaction to particular medications depending on patients' ethnicity and MHC I. People of Han Chinese or Thai ancestry living in Taiwan who also expressed HLA-B*1502, as well as HLA-B*1511, were more likely to have carbamazepine or phenytoin-induced SJS and TEN [11], while those who expressed HLA-B*5801 were more likely to have the reaction after allopurinol exposure [26]. Other MHC allotypes have also been associated with development of SJS and TEN upon exposure of these medications:

- People of Han Chinese descent with HLA-A*2402 have an increased risk of developing SJS and TEN in response to lamotrigine, carbamazepine, and phenytoin [57].

- Some association was also found in people of Japanese [27] and European [35] descent with expression of HLA-B*5801 and allopurinolinduced SJS and TEN.

Other HLA subtypes are associated with multiple types of skin reactions in addition to SJS and TEN upon exposure to the more common culprit medications:

- Expression of HLA-A*3101 in patients who are of European, Japanese, and Indian origin is associated with both SJS and TEN as well as drug reaction with eosinophilia and systemic symptoms (DRESS) [38].

- Patients of Thai ancestry who have the HLA-B*1301 allele tend to have a variety of drug-induced hypersensitivity reactions, including SJS and TEN, because of dapsone [61].

Noting these relationships has led to clinical recommendations in a minority of cases: There are some recommendations that patients of Asian ancestry who express HLA-B*1502 or HLA-A*3101 should undergo screening prior to initiation of carbamazepine treatment [2]. The carbamazepine-mediated reaction was not 
seen in people of Japanese [27], Korean, or European descent [36].

While the HLA subtype is a more commonly recognized genetic risk factor for the development of SJS and TEN, expression of certain cytochrome $\mathrm{P} 450$ enzyme subtypes can also be a predisposing factor: CYP2C9 is drug-metabolizing cytochrome $\mathrm{P} 450$ that metabolizes phenytoin. The CYP2C9*3 variant metabolizes phenytoin at a reduced rate and patients with CYP2C $9 * 3$ have been shown to have higher blood levels of phenytoin at similar doses as well as an increased incidence of SJS and TEN [37].

\section{Pathophysiology}

T-cell activation in SJS and TEN can be precipitated by a variety of stimuli that lead to unintended immune activation, primarily medications and/or their metabolites, but also including infections or malignancies. A favored theory regarding T-cell activation is termed the prohapten concept. A medication or its metabolite can bind with host protein to form a novel antigen. This antigen is taken up by APCs, which process the protein and then display the resulting peptides on the HLA component of their $\mathrm{MHC}$ for presentation to TCRs on CD8+ or CD4+ T cells. Upon binding of the HLA-novel antigen on the APC to the TCR of the CD4 or CD8+ T cell, the T lymphocyte is induced to replicate and these $\mathrm{T}$ cells will target host tissues [31]. Another model is termed the pharmacologic interaction of drugs with the immune system (p-i) concept. In this model, medications or their metabolites noncovalently bond with the type I MHC and TCR, which sets off production of $\mathrm{T}$ cells only. This theory could explain the lack of significant B cell populations found in the skin of patients studied with SJS and TEN.

However, other studies focusing on the role of APCs showed that production of $\mathrm{T}$ cells was absent when pathways responsible for antigen presentation and processing were inhibited by stimulating isolated lymphocytes from patients with known hypersensitivity reactions to sulfamethoxazole. In this same study, when this group of lymphocytes was isolated again and incubated with the inhibitors of antigen presentation, glutaraldehyde and glutathione, sulfamethamethoxazole metabolites were not able to stimulate T-cell proliferation [9]. This study provided positive evidence to support the prohapten concept. In fact, both models could explain in part the disease pathophysiology, although a complete understanding, including a coherent synthesis of the two, has yet to be achieved [55].

In cases of immune activation by means other than medication reaction, the stimuli, whether it is infection or malignancy, can promote propagation of memory $\mathrm{T}$ cells that have activity against self-antigens [44]. The process by which responses to stimuli such as infection or malignancy produces memory T-cell production is termed heterologous immunity. However, in many of these cases, it can be challenging to determine if SJS and TEN is occurring in response to the infection or malignancy itself or in response to its treatment. Furthermore, because such a preponderance of cases are due to medications rather than other causes, it is difficult to develop evidence for the mechanistic model by which these other stimuli propagate T-cell proliferation. Studies that reported lack of representative symptoms in CD8+ T-cell-deficient animal models reinforce the central role of cytotoxic $\mathrm{T}$ cells but do not elucidate the mechanism of their activation [52].

Several cytokines mediate apoptosis in SJS and TEN, including granulysin, perforin, and granzyme B, as well as tumor necrosis factor [46], with related molecules in a supportive role. Cytotoxic T cells can secrete granules that contain granulysin, perforin, and granzyme B. These granules penetrate cell membranes and lead to mitochondrial damage, resulting subsequently in cell death. Analysis of blister fluid from patients with SJS and TEN compared with blister fluid from burn patients showed that the blister fluid from patients with SJS and TEN contained up to twenty times more granulysin, eight times more granzyme B, three times more perforin, and twice as much Fas ligand (Fas-L) [55].

The presence of NK cells and macrophages alongside cytotoxic CD8+ $\mathrm{T}$ lymphocytes, 
which are the predominant immune cell population found in skin and blister fluid samples, supports the hypothesis that these cells behave in a cooperative manner to mediate keratinocyte apoptosis. These cells can secrete or support secretion of members of the tumor necrosis superfamily: tumor necrosis factor (TNF) alpha, CD40L, and Fas-L [1], which promote antigen presentation and other pathways of apoptosis [32].

The exact pathway through which T cells and NK cells produce these mediators has not yet been elucidated, but a study suggests that degranulation is potentially triggered by an interaction between HLA-E, an MHC1b molecule, on keratinocytes and CD94/NKG2CR on T cells [43]. Apoptosis of keratinocytes is the hallmark pathophysiologic feature of SJS and TEN.

\section{Clinical Features}

SJS and TEN most commonly start 4-28 days after the culprit medication is first administered [5]. If a medication is withdrawn and rechallenged, then onset more often occurs within a few hours to a few days [66]. Therefore, newly added drugs should merit more thorough consideration as the causative agent than medications with which the patient has been chronically treated.

The initial symptoms typically experienced include high fevers $\left(>39^{\circ} \mathrm{C}\right)$, pharyngitis, headache, arthralgias, malaise, and conjunctivitis, in addition to the skin lesions [58]. Of note is that fever, malaise, and arthralgias may be present in the first few days prior to any cutaneous involvement [66].

The next phase consists of epidermal detachment, which typically evolves over 5-7 days [62]. Subsequently, the "plateau" phase is characterized by progressive re-epithelization and lasts for a range of several days to several weeks, depending on disease severity and extent of comorbidities. Given the heavy burden of post SJS and TEN sequelae, frequent follow-up is often necessary on recovery to manage all the complications [50].

\section{Mucocutaneous Manifestations}

Mucosal involvement is noted in about $90 \%$ of cases and at least two different sites are typically involved [62].

The lesions characteristic of this syndrome are blisters with mucosal and epidermal detachment that results from epidermal necrosis without significant dermal inflammation. The blisters will develop on top of target lesions or macular lesions with significant involvement of the mucosal layer. These skin lesions can sometimes be confused with erythema multiforme (EM) associated with herpes simplex virus infection or the mucositis and blistering lesions seen in mycoplasma infection in children; however, these other phenomena have a less diffuse distribution than SJS and TEN [58].

When these lesions occur, they first emerge as erythematous, dusky, or purpuric plaques, papules, or blisters, sometimes with formation of vesicles [59]. Sometimes the lesions appear as targetoid lesions with dark centers [69]. They tend to first appear on the face, proximal limbs, and upper trunk. The lesions will grow and become confluent over hours to days, covering the rest of the body [62].

The lesions will then develop into painful ulcerations, which leave eroded areas covered with pseudomembrane and necrosis. Many patients will have tender hemorrhagic erosions with graywhite pseudomembranes and crusts over the vermillion border of the lips on presentation [58].

Nikolsky's sign is specific for SJS and TEN at this stage, but it is not sensitive as it also occurs in Staphylococcal scalded skin syndrome, pemphigus vulgaris, and mucous membrane pemphigoid. Nikolsky's sign is a dermatologic finding in which there is detachment of the epidermis at application of pressure, which results in an erythematous erosion. Nails can be shed in TEN [62].

There is not a strong correlation between severity of cutaneous and mucosal involvement [3].

Following the resolution of SJS and TEN, skin may be hypopigmented, hyperpigmented, or scarred. Nail growth may be abnormal in approximately one-third of surviving patients, with such defects as nail bed pigmentation changes, nail ridging, dystrophic nails, and 
permanent paronychia [62]. A similar proportion of surviving patients will suffer from dry mouth, altered sense of taste, and dental changes [20].

\section{Ophthalmologic Manifestations}

Odynophagia and burning or stinging of the eyes can start early and will portend mucous membrane involvement [62].

Approximately $80 \%$ of cases with have ocular involvement which is characterized by erythema, discharge, lacrimation, tenderness, and photophobia [62]. Severity of initial symptoms correlate with the development of subsequent complications [56].

Ophthalmologic sequelae occur due to altered conjunctival epithelium with abnormal lacrimal film. The ocular complications can include hyperemia, pseudomembrane formation, Sjorgen-like sicca syndrome, purulent conjunctivitis, dry eyes, entropion, trichiasis, symblepharon, inverted or loss of eyelashes, and corneal metaplasia causing corneal erosions/ulcerations [24]. These developments can lead to loss of vision. Bulbar conjunctiva and synechiae between eyelids are subsequent manifestations [56].

Genital, bronchial, esophageal, and pharyngolaryngeal lesions are less frequently occurring characteristics but merit special attention [58]. The genital lesions most often present as dysuria. Synechiae may also form because of genital lesions, especially if overlooked [39].

\section{Bronchial Manifestations}

Although patients may have normal chest radiographical findings and limited or no respiratory symptoms on initial presentation, careful monitoring is needed due to the potential for the rapid development of pulmonary changes. Approximately $25 \%$ of patients with SJS and TEN will have pulmonary involvement, which tends to first be heralded by cough and tachypnea. Interstitial lesions may appear that can lead to acute respiratory distress syndrome (ARDS). Bronchoscopy may be useful to help distinguish between infectious complications of ARDS versus ARDS due to SJS and TEN itself [62].

\section{GI Manifestations}

Necrosis of the esophageal, small bowel, or colonic epithelium occurs rarely but presents as diarrhea with melena, signs of malabsorption [40], and at worst perforation [8].

\section{Renal Manifestations}

Prerenal azotemia is a common complication. Renal failure due to acute tubular necrosis may occur due to apoptosis of the epithelial cells lining the tubules. Other renal manifestations can include proteinuria and hematuria. Elevated blood urea nitrogen (BUN) can signal severity of renal involvement [6].

\section{Hematologic Manifestations}

Neutropenia can occur rarely and tends to involve cases with poor prognosis. Anemia is often present. Eosinophilia does not commonly occur. A common hematologic finding is transient CD4+ lymphopenia, which corresponds to poor $\mathrm{T}$ cell function [62].

\section{Endocrine Manifestations}

Because SJS and TEN represent an extremely catabolic state, insulin secretion is often decreased, and insulin resistance can occur. These changes typically result in hyperglycemia and the development of diabetes. Blood glucose level greater than $14 \mathrm{mM}$ portends severe disease and poor prognosis [5].

\section{Other Manifestations and Laboratory Markers}

Mental status changes because of SJS or TEN on their own are rare. As a result, patients tend to be 
cognizant of the changes, and extreme distress from severe pain is common [66].

Mild transaminitis and amylase elevation are commonly seen but do not affect prognosis [62].

\section{Histopathology}

The pathologic specimen is typically obtained from skin or mucous membrane biopsy; however, similar changes are found in other tissue types involved as well [48]. In the early stages of SJS and TEN, there are sparse apoptotic keratinocytes in the epithelium, which then rapidly changes to a full thickness necrosis with subepidermal detachment. Sweat glands and hair follicles can be involved. The later stages of the disease also feature inflammatory infiltrate of the papillary dermis, made up predominantly of CD8+ T cells and macrophages. Eosinophilia is not commonly seen in TEN [64].

\section{Diagnosis}

While there is no test or list of criteria to prove definitively that a patient has SJS and TEN [62], a skin biopsy can help rule out other conditions with similar presentations. The specimen is best obtained via a shave biopsy or punch biopsy that contains dermis. When preparing the sample for submission, it needs to be collected in formalin, the suspected diagnosis of SJS and TEN should be listed on the accompanying paperwork, and rapid processing (a few hours or less) should be requested [59].

It is difficult to distinguish clinically SJS and TEN from erythema multiforme (EM) early in the clinical presentation, but EM will manifest less extensively and floridly than SJS and TEN, and EM will not have the extensive mucosal involvement that often accompanies SJS and TEN [65].

Limited involvement of mucous membranes should prompt evaluation of alternative diagnoses, such as Staphylococcal scalded skin syndrome in infants, purpura fulminans in younger people, and in adults acute generalized exanthematous pustuosis, phototoxicity, or pressure ulcers
[65]. Trauma-induced scalding or thermal burns merits consideration if loss of consciousness was the first symptom in the patient's presentation [62]. Slower progression of disease would be more typical of linear IgA dermatosis and paraneoplastic pemphigus.

Skin biopsy should allow for differentiation between SJS and TEN and DRESS, exfoliative erythroderma, Staphylococcal scalded skin syndrome, bullous pemphigoid, pemphigus vulgaris, linear IgA dermatosis, paraneoplastic pemphigus, and pemphigus foliaceus. Hematoxylin and eosin staining and direct immunofluorescence will be done to distinguish among these diagnoses [59].

\section{Management}

There is not currently a proven effective cure or treatment for SJS and TEN, so the best approach given current data includes high suspicion for this syndrome, early clinical diagnosis, immediate cessation of suspected culprit medication [19], supportive therapy, and close monitoring for and treatment of complications with high morbidity, such as infection and ophthalmologic sequelae. If a patient has a SCORTEN score of less than or equal to one, has limited skin involvement, and has slower progression of disease, then care can take place in a nonspecialized setting, but all other patients need to be in an ICU or burn unit [16], as patients who receive care in burn units often have better morbidity and mortality outcome [33]. A dermatologic specialist should be consulted in all suspected cases.

\section{Nonpharmacologic Management/ Supportive Care}

Assessment of vital signs is an important first step in the evaluation of patient with suspected SJS or TEN as tachypnea and hypoxia can signal respiratory alkalosis from respiratory involvement [62].

Massive fluid loss through the skin lesions should be treated with aggressive fluid 
resuscitation as fluid loss causes hypotension due to hypovolemia, hypoalbuminemia, electrolyte disturbances, and renal dysfunction. While large doses of intravenous fluids are administered, smaller volumes than what are typically used for burns can be given due to the lack of interstitial edema in SJS and TEN [62].

Other supportive therapies in these cases usually include hemodynamic monitoring and stabilization, prophylaxis against infection, nutrient supplementation and/or replacement, temperature management, analgesia, and thorough care of skin, eyes, and mucous membranes [62].

Infectious complications are the first sequelae to appear and since sepsis is the primary cause of mortality in SJS and TEN, aggressive treatment is indicated [42]. The infectious agents most commonly detected are Staphylococcus aureus and Pseudomonas spp. As one-third of positive blood cultures in these patients contain noncutaneous Enterobacteriae, bacterial translocation from the GI tract is thought to be a common means of infection. Besides frequent daily mouth rinse with antiseptic or antifungal solution, prophylactic antibiotics are not indicated. Instead, careful aseptic technique should be stressed. Frequent culture specimens should be obtained from skin, blood, and urine [13].

Surgical debridement of wounds is not recommended since it can worsen skin lesions; however, the best methods for addressing the cutaneous lesions and optimizing skin care have not yet been determined [14].

Ocular lesions should be assessed by an ophthalmologist daily. Treatment with preservativefree emollients, antiseptic or antibiotic eye drops, and vitamin $\mathrm{A}$ are the interventions recommended early in the disease course to limit subsequent development of complications. These treatments tend to be more effective if administered earlier [64]. A retrospective review of patients with ocular complications of SJS and TEN who were fitted with scleral lens noted reduction in photophobia and tenderness [49].

Suction to prevent aspiration pneumonitis may be indicated in cases with oropharyngeal involvement [5].

\section{Pharmacologic Management}

Among the additional treatments to consider are several immunosuppressants, but these therapies could be a hindrance to recovery in cases complicated by infection [10].

\section{Steroids}

The efficacy of steroids in treatment of SJS and TEN remains to be elucidated, but this class of drugs remains the standard of care as first-line therapy in TEN after or in addition to supportive care [54]. If steroids are given, high dose pulse therapy is favored over smaller doses administered over a longer time period. Prednisone $1-2 \mathrm{mg} / \mathrm{kg}$ daily might be helpful early in the disease process, but prolonged use has led to increased mortality [51]. No prospective studies examining use of steroids compared to supportive care alone have yet been performed, but a large cohort study did not show any meaningful difference in survival with the use of steroids versus best supportive care [53].

\section{Cyclosporine}

Administration of cyclosporine could be considered based on the theoretical plausibility of the putative mechanism of action and several case reports and series [10]. Cyclosporine-mediated cytokine activation, CD8+ cell inhibition, Fas-L inhibition, NFKB inhibition, and TNF-alpha inhibition have all been hypothesized to affect SJS and TEN. Early administration of cyclosporine $\mathrm{A}$ in a couple case series at $3 \mathrm{mg} / \mathrm{kg}$ daily [63] or twice daily [3] has been described as resulting in lower than expected mortality rates than could be anticipated with steroid treatment.

\section{IVlg}

Treating SJS and TEN with IVIg has been recommended in some cases, but the overall effectiveness of this approach is still controversial [47].

The proposed mechanism of action that led originally to the consideration of IVIg as treatment is as follows: IVIg can act as a blocking antibody, which would interfere with the 
Fas ligand-induced keratinocyte apoptosis that underlies this cutaneous reaction. However, examination of blister fluid and cells from wounds of patients with SJS and TEN contained two to four times as much granulysin as compared with Fas-ligand. This finding has led to the reconsideration of the putative mechanism of action described above [55].

Some reviews and retrospective analyses with smaller enrollments including adults who had received IVIg for SJS and TEN demonstrated a mortality benefit when patients had received IVIg in doses $>2 \mathrm{~g} / \mathrm{kg}$ over the course of 3-4 days. However, other studies did not show any benefit [4].

The efficacy of IVIg is likely dependent on timing of administration (early or late in disease course), variability in each IVIg dose, dose of IVIg given, and patient's morbidity burden, particularly renal failure [10].

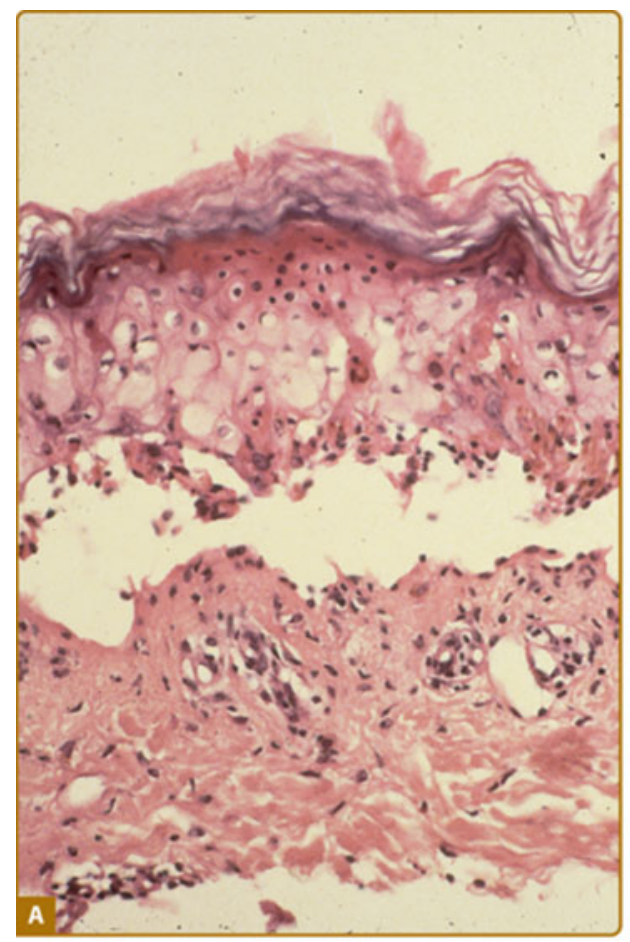

Fig. 1 Histologic appearance of toxic epidermal necrolysis. (a) Eosinophilic necrosis of the epidermis in the peak stage, with little inflammatory response in the

\section{Plasmapheresis}

Plasmapheresis is thought to work by filtering off the inciting agent (the autoantibody or medication and/or its metabolites) or its downstream mediators [54]. Case series have been examined in which TEN patients received plasmapheresis with [34] or without [15] IVIg daily or every other day. These studies demonstrated lower than expected mortality. Reviews of plasmapheresis used in conjunction with pulse dose steroids have concluded that this combination could result in lower mortality rates or improved time to recovery [70]. Some case series suggested beneficial responses for patients refractory to other therapies [60]. In other case series, patients failed to exhibit any benefit from the use of plasmapheresis [17]. Plasmapheresis has been covered by insurance in Japan since 2006 as a second-line therapy for TEN [69]. The American Society of Apheresis lists plasmapheresis as a category 3 grade $2 \mathrm{~B}$ recommendation [54].

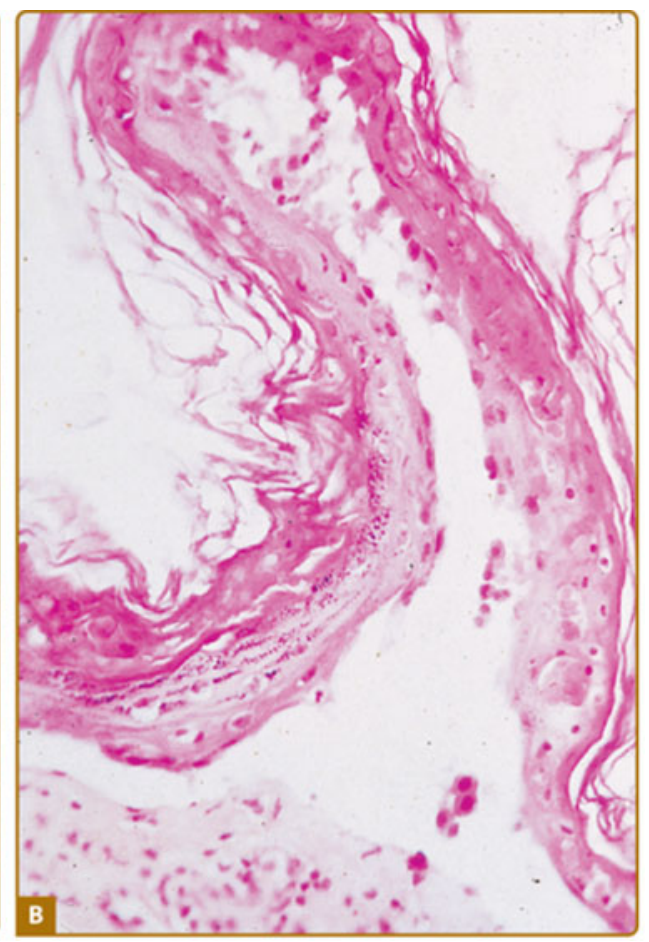

dermis. Note cleavage in the junction zone. (b) The completely necrotic epidermis has detached from the dermis and folded like a sheet 


\section{Thalidomide}

Thalidomide has been investigated for use in treatment of SJS and TEN, but its use cannot be recommended based on current evidence [36]. Because keratinocyte apoptosis in TEN is thought to be mediated by TNF alpha, it was hypothesized that the thalidomide-mediated TNF alpha inhibitor activity might grant it a role in the treatment of TEN. A prospective, randomized controlled study comparing the use of thalidomide to placebo in patients with TEN who had not received any therapy closed early after enrolling 22 of the planned 50 patients when 13 of the 22 patients died over the 16 months enrollment had been open. Upon unblinding of the results, it was found that 10 patients out of 12 had died in the thalidomide group, and 3 people out of 10 had died in the placebo group. The trial was then stopped at the recommendation of the group's safety board [29].

\section{Prevention}

Upon recovery, the patient should be alerted to the culprit medication and advised to never take that medication again. The patient should also be warned that other medications in the same class may cause the same reaction. The medication should be placed on the patient's allergy list and the patient may elect to wear a medical alert bracelet [5].

\section{Prognosis}

Prognosis correlates with extent of mucocutaneous necrosis, with SJS having a mortality rate of approximately $5-10 \%$ and TEN having a mortality rate of $30-40 \%$ [28]. Most deaths occur in elderly patients, with death being more likely in patients with greater comorbidity burden [67]. Sepsis is the primary cause of death in patients with SJS and TEN [33]. Pulmonary complications occur in approximately $15 \%$ of cases. Multisystem organ failure is noted in at least $30 \%$ of patients with SJS and TEN [45]. Purported cause does not play a role in risk of mortality. The SCORTEN scale allows for estimation of risk of death. Each of the following prognostic factors in the SCORTEN scoring system is worth one point: age greater than 40 years old, heart rate greater than 120 beats per minute, presence of malignancy, BSA greater than $10 \%$ involved, serum urea greater than $10 \mathrm{mM}$, serum bicarbonate less than $20 \mathrm{mM}$, and serum glucose greater than $14 \mathrm{mM}$. A score of $0-1$ is associated with a mortality rate of $3.2 \%, 2$ with $12.1 \%, 3$ with $35.8 \%$, 4 with $58.3 \%$, and 5 or greater with $90 \%$ mortality [10]. Serum bicarbonate less than $20 \mathrm{mM}$ indicates pulmonary involvement and also portends poor prognosis. GI involvement also indicates elevated morbidity and mortality should be anticipated [5].

Among patients who survive, complications are very common. Ninety percent of people in a cohort of European patients who remained alive after experiencing SJS and TEN had multiple persistent complications and a perception of worsened quality of life (Fig. 1).

\section{References}

1. Abe R, Shimizu T, Shibaki A, Nakamura H, Watanabe H, Shimizu H. Toxic epidermal necrolysis and Stevens-Johnson syndrome are induced by soluble Fas ligand. Am J Pathol. 2003;162(5):1515-20.

2. Amstutz U, Shear NH, Rieder MJ, Hwang S, Fung V, Nakamura H, Connolly MB, Ito S, Carleton BC, CPNDS clinical recommendation group. Recommendations for HLA-B*15:02 and HLA-A*31:01 genetic testing to reduce the risk of carbamazepine-induced hypersensitivity reactions. Epilepsia. 2014;55(4): 496-506.

3. Arevalo JM, Lorente JA, González-Herrada C, Jiménez-Reyes J. Treatment of toxic epidermal necrolysis with cyclosporine A. J Trauma. 2000;48(3): 473-8.

4. Bachot N, Revuz J, Roujeau JC. Intravenous immunoglobulin treatment for Stevens-Johnson and toxic epidermal necrolysis: a prospective noncomparative study showing no benefit on mortality or progression. Arch Dermatol. 2003;139(1):33-6.

5. Bastuji-Garin S, Fouchard N, Bertocchi M, Roujeau JC, Revuz J, Wolkenstein P. SCORTEN: a severity-of-illness score for toxic epidermal necrolysis. J Invest Dermatol. 2000;115(2):149-53.

6. Blum L, Chosidow O, Rostoker G, Philippon C, Revuz J, Roujeau JC. Renal involvement in toxic epidermal necrolysis. J Am Acad Dermatol. 1996; 34(6):1088-90. 
7. Breslin ME, Garcia-Lloret M, Braskett M. A fatal case of drug reaction with eosinophilia and systemic symptoms (DRESS) - Stevens Johnson (SJS)/Toxic epidermal necrolysis (TEN) in the setting of strongyloides infection: treatment considerations. J Allergy Clin Immunol. 2015;135(2):AB124.

8. Carter FM, Mitchell CK. Toxic epidermal necrolysis an unusual cause of colonic perforation. Report of a case. Dis Colon Rectum. 1993;36:773.

9. Castrejon JL, Berry N, El-Ghaiesh S, Gerber B, Pichler WJ, Naisbitt DJ. Stimulation of human T cells with sulfonamides and sulfonamide metabolites. J Allergy Clin Immunol. 2010;125(2):411-8.e4.

10. Chen ST, Velez NF, Saavedra AP. Adverse cutaneous drug reactions. In: McKean SC, Ross JJ, Dressler DD, Scheurer DB, editors. Principles and practice of hospital medicine, 2e. New York; 2017. Available via ACCESS MEDICINE. http://accessmedicine.mhmedi cal.com $/$ content.aspx ?bookid $=1872 \&$ sectionid $=1469$ 80847. Accessed 23 May 2018.

11. Chung WH, Hung SI, Hong HS, Hish MS, Yang LC, Ho HC, Wu JY, Chen YT. Medical genetics: a marker for Stevens Johnson syndrome. Nature. 2004; 428(6982):486.

12. Chung WH, Hung SI, Yang JY, Su SC, Huang SP, Wei CY, Chin SW, Chiou CC, Chu SC, Ho HC, Yang $\mathrm{CH}$, Lu CF, Wu JY, Liao YD, Chen YT. Granulysin is a key mediator for disseminated keratinocyte death in Stevens-Johnson syndrome and toxic epidermal necrolysis. Nat Med. 2008;14(12): 1343-50.

13. de Prost N, Ingen-Housz-Oro S, Duong Ta, ValeyrieAllanore L, Legrand P, Wolkenstein P, Brochard L, Brun-Buisson C, Roujeau JC. Bacteremia in StevensJohnson syndrome and toxic epidermal necrolysis: epidemiology, risk factors, and predictive value of skin cultures. Medicine (Baltimore). 2010;89(1):28-36.

14. Dorafshar AH, Dickie SR, Cohn AB, Aycock JK, O'Connor A, Tung A, Gottlieb LJ. Antishear therapy for toxic epidermal necrolysis: an alternative treatment approach. Plast Reconstr Surg. 2008;122(1):154-60.

15. Egan CA, Grant WJ, Morris SE, Saffle JR, Zone JJ. Plasmapheresis as an adjunct treatment in toxic epidermal necrolysis. J Am Acad Dermatol. 1999;40(3): 458-61.

16. Ellis MW, Oster CN, Turiansky GW, Blanchard JR. A case report and a proposed algorithm for the transfer of patients with Stevens-Johnson syndrome and toxic epidermal necrolysis to a burn center. Mil Med. 2002; 167(8):701-4.

17. Firoz BF, Henning JS, Zarzabal LA, Pollock BH. Toxic epidermal necrolysis: five years of treatment experience from a burn unit. J Am Acad Dermatol. 2012; 67(4):630-5.

18. Frey N, Jossi J, Bodmer M, Bircher A, Jick SS, Meier CR, Spoendlin J. The epidemiology of Stevens-Johnson syndrome and toxic epidermal necrolysis in the UK. J Invest Dermatol. 2017;137(6): 1240-7.
19. Garcia-Doval I, LeCleach L, Bocquet H, Otero XL, Roujeau JC. Toxic epidermal necrolysis and StevensJohnson syndrome. Does early withdrawal of causative drugs decrease the risk of death? Arch Dermatol. 2000;136(3):323-7.

20. Gaultier F, Rochefort J, Landru MM, Allanore L, Naveau A, Roujeau JC, Gogly B. Severe and unrecognized dental abnormalities after drug-induced epidermal necrolysis. Arch Dermatol. 2009;145(11):1332-3.

21. Goldsmith LA, Katz SI, Gilchrest BA, Paller AS, Leffell DJ, Wolff K (8th edition) Fitzpatrick's Dermatology in General Medicine. McGraw Hill, New York. 2012.

22. Gillis NK, Hicks JK, Bell GC, Daily AJ, Kanetsky PA, McLeod HL. Incidence and triggers of StevensJohnson syndrome and toxic epidermal necrolysis in a large cancer patient cohort. J Invest Dermatol. 2017; 137(9):2021-3

23. Gravante G, Delogu D, Marianetti M, Esposito G, Montone A. Toxic epidermal necrolysis and StevenJohnson syndrome in oncologic patients. Eur Rev Med Pharmacol Sci. 2007;11(4):269-74.

24. Gueudry J, Roujeau JC, Binaghi M, Soubrane G, Muraine M. Risk factors for the development of ocular complications of Stevens-Johnson syndrome and toxic epidermal necrolysis. Arch Dermatol. 2009;145(2): 157-62.

25. Hsu DY, Brieva J, Silverberg NB, Silverberg JI. Morbidity and mortality of Stevens-Johnson syndrome at toxic epidermal necrolysis in United States adults. J Invest Dermatol. 2016;136(7):1387-97.

26. Hung SI, Chung WH, Liou LB, Chu CC, Lin M, Huang HP, Lin YL, Lan JL, Yang LC, Hong HS, Chen MJ, Lai PC, Wu MS, Lai PC, Wu MS, Chu CY, Wang $\mathrm{KH}$, Chen $\mathrm{CH}$, Fann $\mathrm{CS}$, Wu JY, Chen YT. HLA-B*5801 allele as a genetic marker for severe cutaneous adverse reactions caused by allopurinol. Proc Natl Acad Sci USA. 2005;102(11):4134-9.

27. Kaniwa N, Saito Y, Aihara M, Matsunaga K, Tohkin M, Kurose K, Sawada J, Furuya H, Takahashi Y, Muramatsu M, Kinoshita S, Abe M, Ikeda H, Kashiwagi M, Song Y, Ueta M, Sotozono C, Kkezawa Z, Hasegawa R, JSAR research group. HLA-B locus in Japanese patients with anti-epileptics and allopurinol-related Stevens-Johnson syndrome and toxic epidermal necrolysis. Pharmacogenomics. 2008;9(11):1617-22.

28. Kardaun SH, Jonkman MF. Dexamethasone pulse therapy for Stevens-Johnson syndrome/toxic epidermal necrolysis. Acta Derm Venereol. 2007;87(2):144-8.

29. Khalaf D, Toema B, Dabbour N, Jehani F. Toxic epidermal necrolysis associated with severe cytomegalovirus infection in a patient on regular hemodialysis. Mediterr J Hematol Infect Dis. 2011;3(1):e2011004.

30. Kinoshita Y, Saeiki H. A review of toxic epidermal necrolysis management in Japan. Allergol Int. 2017; 66(1):36-41.

31. Koutlas IG. Diseases of the oral cavity. Clinical dermatology Eds. Carol Soutor, and Maria K. Hordinsky. New 
York, NY: McGraw-Hill. 2013. http://accessmedicine. mhmedical.com.lp.hscl.ufl.edu/content.aspx?bookid= $2184 \&$ sectionid $=165461482$.

32. Le Cleach L, Delaire S, Boumsell L, Bagot M, Bourgault-Villada I, Bensussan A, Roujeau JC. Blister fluid $\mathrm{T}$ lymphocytes during toxic epidermal necrolysis are functional cytotoxic cells which express human natural killer inhibitory receptors. Clin Exp Immunol. 2000;119(1):225-30.

33. Lissia M, Mulas P, Bulla A, Rubino C. Toxic epidermal necrolysis (Lyell's disease). Burns. 2010;36(2): 152-63.

34. Lissia M, Figus A, Rubino C. Intravenous immunoglobulins and plasmapheresis combined treatment in patients with severe toxic epidermal necrolysis: preliminary report. Br J Plast Surg. 2005;58:504.

35. Lonjou C, Borot N, Sekula P, Ledger N, Thomas L, Halevy S, Naldi L, Bouwes-Bavinck JN, Sidoroff A, de Toma C, Schumacher M, Roujeau JC, Hovnanian A, Mockenhaupt M, RegiSCAR study group. A European study of HLA-B in Stevens-Johnson syndrome and toxic epidermal necrolysis related to five high-risk drugs. Pharmacogenet Genomics. 2008;18(2):99-107.

36. Lonjou C, Thomas L, Borot N, Ledger N, de Toma C, Lelouet H, Graf E, Schmacher M, Hovnanian A, Mockenhaupt M, Roujeau JC, RegiSCAR Group. A marker for Stevens-Johnson syndrome: ethnicity matters. Pharmacogenomics J. 2006;6(4):265-8.

37. Manuyakorn W, Siripool K, Kamchaisatian W, Pakakasama S, Visudtibhan A, Vilaiyuk S, Rujirawat T, Benjaponpitak S. Phenobarbital-induced severe cutaneous adverse drug reactions are associated with CYP2C19*2 in Thai children. Pediatr Allergy Immunol. 2014;24(3):299-303.

38. McCormack M, Alfirevic A, Bourgeois S, Farrell JJ, Kasperaviciute D, Carrington M, Sills GJ, Marson T, Jia X, de Bakker PI, Chinthapalli K, Molokhia M, Johnson MR, O'Conner GD, Chalia E, Alhusaini S, Shianna KV, Radtke RA, Keinzen EL, Walley N, Pandolfo M, Pichler W, Park BK, Depondt C, Sisodiya SM, Goldstein DB, Deloukas P, Delanty N, Cavalleri GL, Pirmohamed M. HLA-A*3101 and carbamazepine-induced hypersensitivity reactions in Europeans. N Engl J Med. 2011;364(12):1134-43.

39. Meneux E, Wolkenstein P, Haddad B, Roujeau JC, Revuz J, Paniel BJ. Vulvovaginal involvement in toxic epidermal necrolysis: a retrospective study of 40 cases. Obstet Gynecol. 1998;91(2):283-7.

40. Michel P, Joly P, Ducrotte P, Hemet J, Leblanc I, Lauret P, Lerebours E, Colin R. Ileal involvement in toxic epidermal necrolysis (Lyell syndrome). Dig Dis Sci. 1993;38(10):1938-41.

41. Mockenhaupt M, Viboud C, Dunant A, Naldi L, Halevy S, Bouwes Bavinck JN, Sidoroff A, Schneck J, Roujeau JC, Flahault A. Stevens-Johnson syndrome and toxic epidermal necrolysis: assessment of medication risks with emphasis on recently marketed drugs. The EuroSCAR-study. J Invest Dermatol. 2008;128(1):35-44.
42. Mockenhaupt M. Severe drug-induced skin reactions: clinical pattern, diagnostics and therapy. J Dtsch Dermatol Ges. 2009; 7:142.

43. Morel E, Escamochero S, Cabanas R, Dias R, Fiandor A, Bellon T. CD94/NKG2R is a killer effector molecule in patients with Stevens-Johnson syndrome and toxic epidermal necrolysis. J Allergy Clin Immunol. 2010;125(3):703-10.

44. Okamoto-Uchida Y, Nakamura R, Sai K, Imatoh T, Matsunaga K, Aihara M, Saito Y. Effect of infectious disease on the pathogenesis of Stevens-Johnson syndrome and toxic epidermal necrolysis. Biol Pharm Bull. 2017;40(9):1576-80.

45. Palmieri T, Greenhalgh DG, Saffle JR, Spence RJ, Peck MD, Jeng JC, Mozingo DW, Yowler CJ, Sheridan RL, Ahrenholz DH, Caruso DM, Foster KN, Kagan RJ, Voigt DW, Purdue GF, Hunt JL, Wolf S, Molitor F. A multicenter review of toxic epidermal necrolysis treated in U.S. burn centers at the end of the twentieth century. J Burn Care Rehabil. 2002; 23(2):87-96.

46. Paquet P, Nikkels A, Arrese JE, Vanderkelen A, Piérard GE. Macrophages and tumor necrosis factor alpha in toxic epidermal necrolysis. Arch Dermatol. 1994;130(5):605-8.

47. Prins C, Kerdel FA, Padilla RS, Hunziker T, Chimenti S, Viard I, Mauri DN, Flynn K, Trent J, Margolis DJ, Saurat JH, French LE, TEN-IVIG Study Group. Toxic epidermal necrolysis-intravenous immunoglobulin. Treatment of toxic epidermal necrolysis with high-dose intravenous immunoglobulins. Arch Dermatol. 2003;139(1):26-32.

48. Quinn AM, Brown K, Bonish BK, Curry J, Gordon KB, Sinacore J, Gamelli R, Nickoloff BJ. Uncovering histologic criteria with prognostic significance in toxic epidermal necrolysis. Arch Dermatol. 2005;141(6):683-7.

49. Rosenthal P, Cotter J. The Boston Scleral Lens in the management of severe ocular surface disease. Ophthalmol Clin North Am. 2003;16(1):89-93.

50. Roujeau JC, Kelly JP, Naldi L, Rzany B, Stern RS, Anderson T, Auquier A, Bastuji-Garin S, Correia O, Locati F, et al. Medication use and the risk of StevensJohnson syndrome or toxic epidermal necrolysis. N Engl J Med. 1995;333(24):1600-7.

51. Rzany B, Hering O, Mockenhaupt M, Schröder W, Goerttler E, Ring J, Schöpf E. Histopathological and epidemiological characteristics of patients with erythema multiforme major, Stevens-Johnson syndrome and toxic epidermal necrolysis. Br J Dermatol. 2006; 135(1):6-11.

52. Saito N, Yoshioka N, Abe R, Qiao H, Fujita Y, Hoshina D, Suto A, Kase S, Kitaichi N, Ozaki M, Shimizu H. Stevens-Johnson syndrome/toxic epidermal necrolysis mouse model generated by using PBMCs and the skin of patients. J Allergy Clin Immunol. 2013;131(2):434-41.

53. Schneck J, Fagot JP, Sekula P, Sassolas B, Roujeau JC, Mockenhaupt M. Effects of treatments on the mortality 
of Stevens-Johnson syndrome and toxic epidermal necrolysis: a retrospective study on patients included in the prospective EuroSCAR Study. J Am Acad Dermatol. 2008;58(1):33-40.

54. Schwartz J, Padmanabhan A, Aqui N, Balogun RA, Connelly-Smith L, Delaney M, Dunbar M, Dunbar NM, Witt V, Wu Y, Shaz BH. Guidelines on the use of therapeutic apheresis in clinical practice evidence based approach from the Writing Committee of the American Society for Apheresis: the seventh special issue. J Clin Apher. 2016;31(3):149-62.

55. Schwartz RA, McDonough PH, Lee BW. Toxic epidermal necrolysis: Part 1. Introduction, history, classification, clinical features, systemic manifestations, etiology, and immunopathogenesis. J Am Acad Dermatol. 2013;69(2):173.e1-13.

56. Shay E, Kheirkhah A, Liang L, Sheha H, Gregory DG, Tseng SC. Amniotic membrane transplantation as a new therapy for the acute ocular manifestations of Stevens-Johnson syndrome and toxic epidermal necrolysis. Surv Ophthalmol. 2009;54(6):686-96.

57. Shi YW, Min FL, Zhou D, Qin B, Wang J, Hu FY, Cheung YK, Zhou JH, Hu XS, Zhou JQ, Zhou LM, Zheng ZZ, Pan J, He N, Liu ZS, Hou YQ, Lim KS, Ou YM, Hui-Ping Khor A, Ng CC, Mao BJ, Liu XR, Li BM, Kuan YY, Yi YH, He XL, Deng XY, Su T, Kwan P, Laio WP. HLA-A*24:02 as a common risk factor for antiepileptic drug-induced cutaneous adverse reactions. Neurology. 2017;88(23):2183-91.

58. Shinkai K, Stern RS, Wintroub BU. Cutaneous drug reactions. In: Kasper D, Fauci A, Hauser S, Longo D, Jameson J, Loscalzo J, editors. Harrison's principles of internal medicine, 19e. New York; 2014. Available in ACCESS MEDICINE. http://accessmedicine.mhmedi cal.com/content.aspx?bookid $=1130 \&$ sectionid $=7972$ 7466. Accessed 23 May 2018.

59. Smith C. Erythema multiforme, Stevens-Johnson syndrome, toxic epidermal necrolysis, staphylococcal scalded skin syndrome. In: Soutor C, Hordinsky MK, editors. Clinical dermatology. New York; 2013. Available via ACCESS MEDICINE. http://accessmedicine. mhmedical.com.lp.hscl.ufl.edu/content.aspx?bookid= 2184\&sectionid=165460970. Accessed 28 May 2018.

60. Szczeklik W, Nowak I, Seczynska B, Sega A, Krolikowski W, Musial J. Beneficial therapeutic effect of plasmapheresis after unsuccessful treatment with corticosteroids in two patients with severe toxic epidermal necrolysis. Ther Apher Dial. 2010;14(3): 354-7.

61. Tempark T, Satapornpong P, Rerknimitr P, Nakkam N, Saksit N, Wattanakrai P, Jantararoungtong T, Koomdee N, Mahakkanukrauh A, Tassaneeyakul W, Suttisai S, Pratoomwun J, Klaewsongkram J,
Rerkpattanapipat T, Sukasem C. Dapsone-induced severe cutaneous adverse drug reactions are strongly linked with HLA-B*13: 01 allele in the Thai population. Pharmacogenet Genomics. 2017;27(12):429-37.

62. Valeyrie-Allanore LL, Roujeau J. Epidermal necrolysis (Stevens-Johnson syndrome and toxic epidermal necrolysis). In: Goldsmith LA, Katz SI, Gilchrest BA, Paller AS, Leffell DJ, Wolff $\mathrm{K}$ (8th edition). Fitzpatrick's dermatology in general medicine, McGraw Hill, New York; 2012. Available via ACCESS MEDICINE. http://accessmedi cine. mhmedical.com/content.aspx?bookid $=392 \&$ secti onid $=$ 41138737. Accessed 28 May 2018.

63. Valeyrie-Allanore L, Wolkenstein P, Brochard L, Ortonne N, Maître B, Revuz J, Bagot M, Roujeau JC. Open trial of ciclosporin treatment for Stevens-Johnson syndrome and toxic epidermal necrolysis. $\mathrm{Br} \mathrm{J}$ Dermatol. 2010;163(4):847-53.

64. Williams GP, Mudhar HS, Leyland M. Early pathological features of the cornea in toxic epidermal necrolysis. Br J Ophthalmol. 2007;91(9):1129-32.

65. Williams R, Hodge J, Ingram W. Indications for intubation and early tracheostomy in patients with StevensJohnson Syndrome and Toxic Epidermal Necrolysis. Am J Surg. 2016;211(4):684-688e1.

66. Wolff K, Johnson R, Saavedra AP, Roh EK. The acutely ill and hospitalized patient. In: Fitzpatrick's color atlas and synopsis of clinical dermatology, 8e. New York; 2012. Available via ACCESS MEDICINE. http://accessmedicine.mhmedical.com/ content.aspx ?bookid $=2043 \&$ sectionid $=154897923$. Accessed 23 May 2018.

67. Wolkenstein P, Latarjet J, Roujeau JC, Duguet C, Boudeau S, Vaillant L, Maignan M, Schuhmacher MH, Milpied B, Pilorget A, Bocquet H, Brun-Buisson C, Revuz J. Randomized comparison of thalidomide versus placebo in toxic epidermal necrolysis. Lancet. 1998;352(9140):1586-9.

68. Wu J, Lee YY, Su SC, Wu TS, Kao KC, Huang CC, Chang WC, Yang CH, Chung WH. Stevens-Johnson syndrome and toxic epidermal necrolysis in patients with malignancies. $\mathrm{Br} \mathrm{J}$ Dermatol. 2015;173(5): 1224-31.

69. Yamane Y, Matsukura S, Watanabe Y, Nakamura K, Kambara T, Ikezawa Z, Aihara M. Retrospective analysis of Stevens-Johnson syndrome and toxic epidermal necrolysis in 87 Japanese patients - treatment and outcome. Allergol Int. 2016;65(1):74-81.

70. Ye LP, Zhang C, Zhu QX. The effect of intravenous immunoglobulin combined with corticosteroid of the progression of Stevens-Johnson syndrome and toxic epidermal necrolysis: a meta-analysis. PLoS One. 2016;11(11):e0167120. 